\title{
Erratum to: Protective management of trees against debarking by deer negatively impacts bryophyte diversity
}

\section{Yoshitaka Oishi}

Published online: 1 December 2013

(C) Springer Science+Business Media Dordrecht 2013

\section{Erratum to: Biodivers Conserv (2011) 20:2527-2536 DOI 10.1007/s10531-011-0090-4}

The author would like to correct the incorrect figures and captions in the original publication of the article.

The positions of plots A, B, D, E in Fig. 1 were not exact. The correct figure is provided in this Erratum.

In the caption of Fig. 2, the word "right" in parentheses should be left and the "left" in parentheses should be "right". The correct caption is given below.

Fig. 2 Examples of tree trunks with (right) and without (left) wire mesh. The middle part of the tree trunk that does not have wire mesh has been debarked by deer.

In Fig. 3, the bars for sampling plot C, D, and $\mathrm{E}$ were not exact. The correct figure is provided in this Erratum.

The online version of the original article can be found under doi:10.1007/s10531-011-0090-4.

Y. Oishi $(\bowtie)$

Laboratory of Applied Plant Ecology and Landscape Ecology, Department of Forest Science, Faculty of Agriculture, Shinshu University, 8304 Minami-minowa, Kami-ina, Nagano 399-4598, Japan

e-mail: oishiy@shinshu-u.ac.ip 

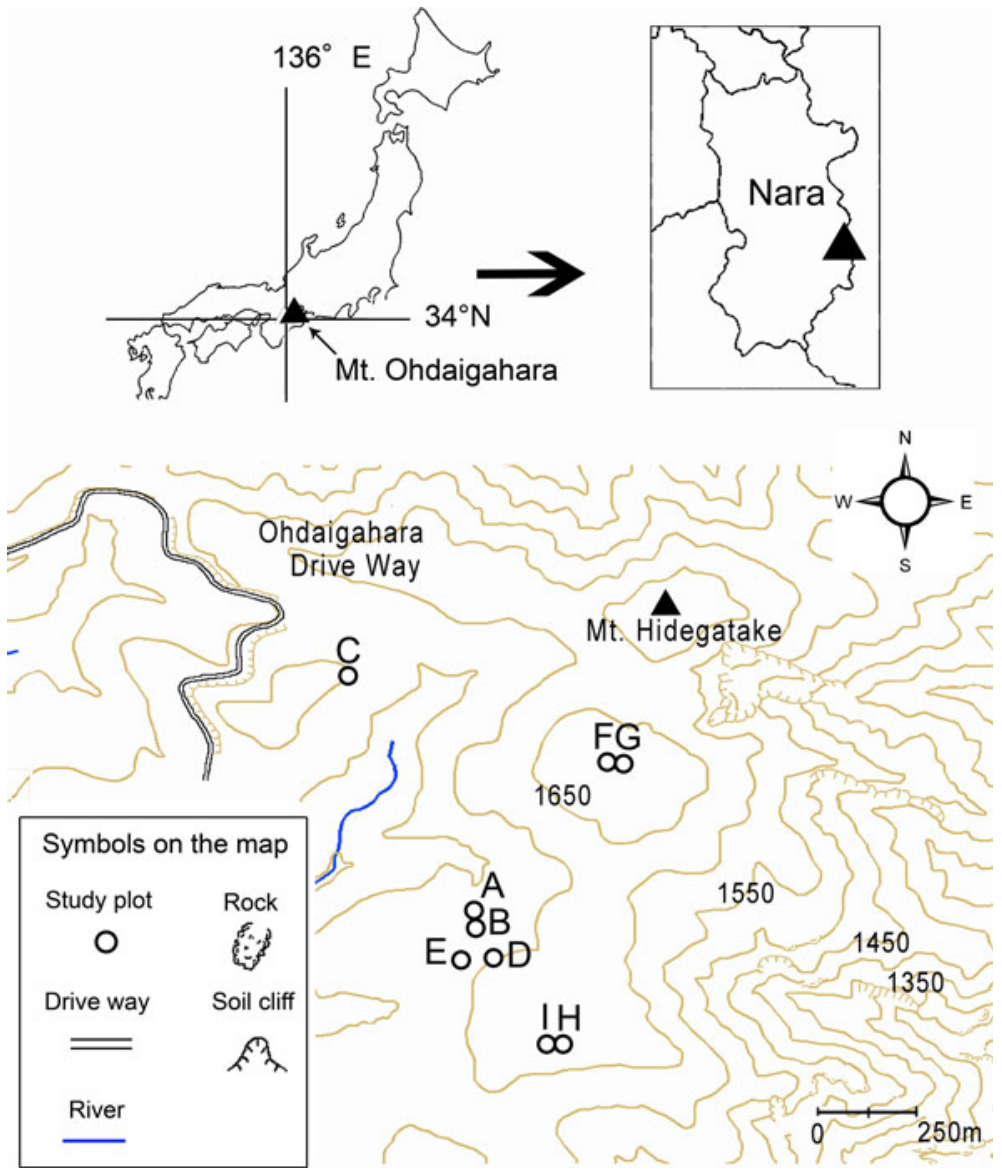

Fig. 1 Location of Mt. Ohdaigahara and the study plot. This mountain is located on the Kii Peninsula in Kinki District, central Japan
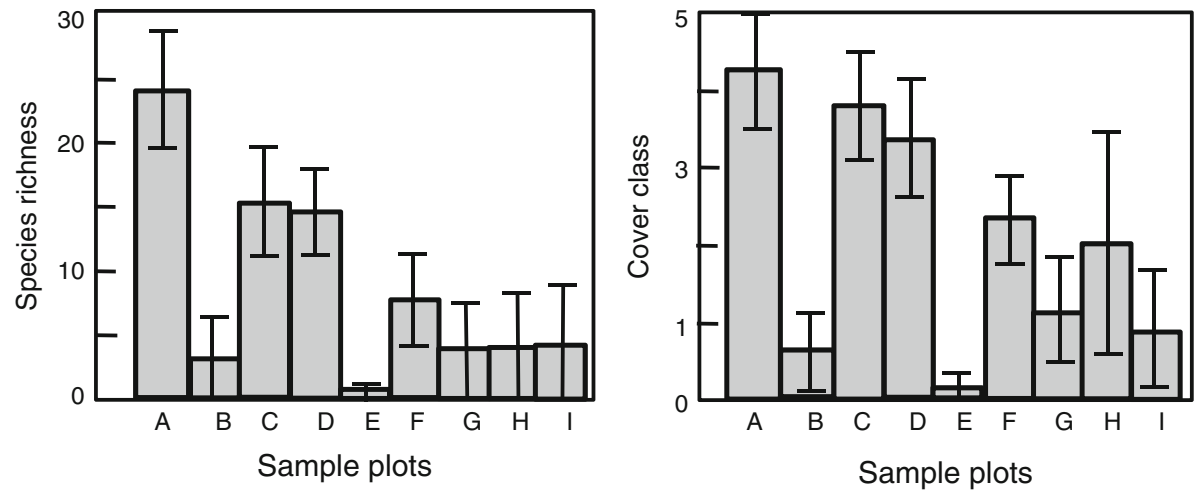

Fig. 3 Comparison of species richness and epiphytic bryophyte cover on P. jezoensis var. hondoensis trees in each plot. The bars represent the mean value of species richness and epiphyte cover on a single tree, and the error bars represent the corresponding standard deviations 